\title{
Rehabilitation of Welded Joints by Ultrasonic Impact Treatment (UIT)
}

\section{Hans-Peter GÜNTHER}

Senior Researcher

University of Stuttgart

Germany

hp.guenther@ke.uni-stuttgart,de

Hans-Peter Günther, born 1971, received his $\mathrm{PhD}$ from the Univ. of Stuttgart in 2001. Since 2001 he is senior researcher at the Univ. of Stuttgart.

\section{Ulrike KUHLMANN}

Professor

University of Stuttgart

Germany

sekretariat@ke.uni-stuttgart.de

Ulrike Kuhlmann, born 1957, received her $\mathrm{PhD} 1986$ from the Ruhr-Univ. Bochum. Since 1995 she is professor for steel, timber and composite constructions at the Univ. of Stuttgart.

\author{
André DÜRR \\ Research Engineer \\ University of Stuttgart \\ Germany \\ andre.duerr@ke.uni-stuttgart.de
}

André Dürr, born 1972, received his civil engineering degree from the Univ. of Stuttgart in 1999. He works at Univ. of Stuttgart since 2000 .

\section{Summary}

Due to the increasing traffic and life loading fatigue becomes of high relevance in order to maintain the integrity of existing steel bridge structures. Poor construction details which used to be regarded as less important when applied e.g. to road bridges are nowadays often the starting point of fatigue cracks. Repair and strengthening of welded details are thus of great importance in order to extend the life time and safety of existing bridges. For welded details under fatigue loading one effective possibility to do this is the application of local post-weld treatment methods. This paper presents the application of a relatively new post-weld treatment method called "Ultrasonic Impact Treatment" (UIT). The paper summarizes the results obtained on a series of experimental fatigue tests where UIT has been applied in order to extend the life time of partially damaged non load carrying fillet welded joints.

Keywords: Fatigue cracks, post-weld treatment methods, fatigue life extension, welded joints, strengthening of welded structures, ultrasonic impact treatment

\section{Introduction}

Fatigue is an important issue for the design and maintenance of steel structures subjected to cyclic loading as e.g. bridges, cranes, ships, pressure vessels etc. Especially for bridge structures the aspect of fatigue becomes of major importance due to the ever increasing amount of life loading and/or axles loads as indicated e.g. in Fig. 1 and 2 presenting the development of the average daily traffic volume and axle loads on German highways within the last 50 years [1]. Another point that is responsible for this situation is the fact that in former times poor construction details which used to be regarded as less important when applied to road bridges nowadays become the starting point of fatigue cracks due to the increased traffic volume.

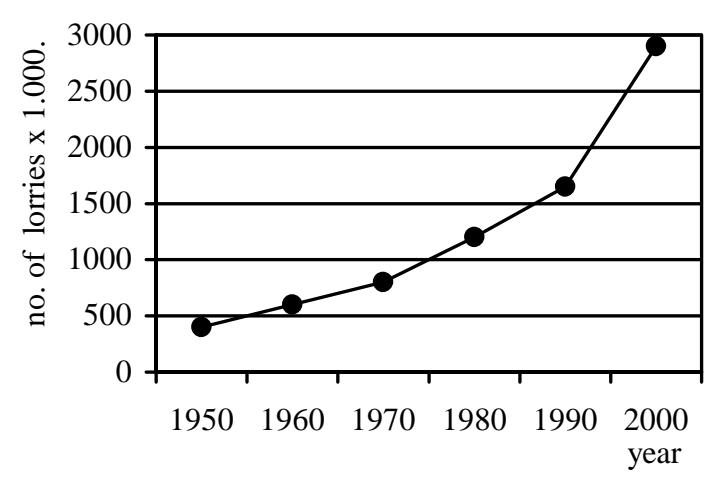

Fig. 1 Development of average daily traffic on German highways [1]

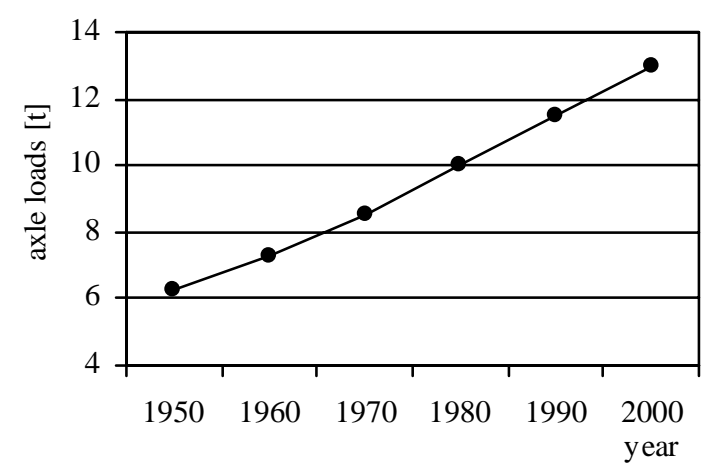

Fig. 2 Development of axle loads on German highways [1] 
As fatigue cracking can remarkably affect the structural function, durability and safety of bridge structures, operators and owners of bridges are more and more faced on looking for reliable, effective and low priced measures to repair and/or strengthen fatigue prone details in order to extend their life time.

Through the advent of the new post-weld treatment technology "Ultrasonic Impact Treatment" (UIT) an advanced method is nowadays available to improve the fatigue life of welded structures not only for new manufactured structures but also for the repair and strengthening of existing structures. In order to quantify the effectiveness of this new method especially for the latter field of application, fatigue testing was carried out on a partially damaged welded transverse stiffener detail in order to quantify the fatigue life extension.

\section{Repair and/or strengthening of existing structures}

\subsection{General}

Whether a structure has to be repaired or strengthened mainly depends on the given fatigue damage situation. If fatigue cracks are detected in a structure retrofit measures have to be undertaken to repair the cracked structural members. If the structure itself or certain details are evaluated to be sensible to fatigue and having no or just shallow cracks, the fatigue performance may be increased by applying adequate strengthening measures. A summary of existing fatigue and repair cases of fatigue loaded welded structures are given e.g. in [2] - [4].

\subsection{Repair and strengthening measures}

The following contains a list according to [2] summarizing the most important repair and strengthening methods:

- removal of cracks

- re-welding

- surface treatments (grinding, shot peening, air hammer peening, TIG dressing, UIT)

- adding plates or fiber reinforced plastic strips (FRP strips)

- bolted splices

- shape improvement

- stop holes

Although there are various repair and strengthening methods available and documented, fundamental research on the effectiveness and on the most suitable area of application of these methods is rarely available. It is e.g. common practice to assume that repaired welded details will have the same fatigue resistance as the original ones, which is not sufficiently verified up to now. The situation becomes even more complicated when applying strengthening methods: the question e.g. arises how much the service life time of a structures can be extended depending on the existing rate of damage. The experimental study described in the following aims to give a first answer to this problem for the application of UIT to extend the life time of existing structures.

\section{Ultra Sonic Impact Treatment (UIT)}

\subsection{General}

The "Ultrasonic Impact Treatment" (UIT) is a relatively new and promising post-weld surface treatment technique that was first invented and patented in the 1970s under the guidance of STATNIKOV [5]. The UIT method involves a deformation treatment of the weld toe by a mechanical hammering at a frequency of around $200 \mathrm{~Hz}$ superposed by ultrasonic treatment at a frequency of $27 \mathrm{kHz}$. The objective of the treatment is to introduce beneficial compressive residual stresses at the weld toe by plastic deformation of the surface and to reduce stress concentration by smoothening of the weld toe profile. The UIT equipment is shown in Fig. 3 and 4. The equipment comprises a relatively lightweight handheld tool and an electronic control box containing the ultrasonic generator. The tool is easy to operate and there are several kinds of heads and tips available which can be chosen on the basis of the surface condition and weld detail to be treated. 


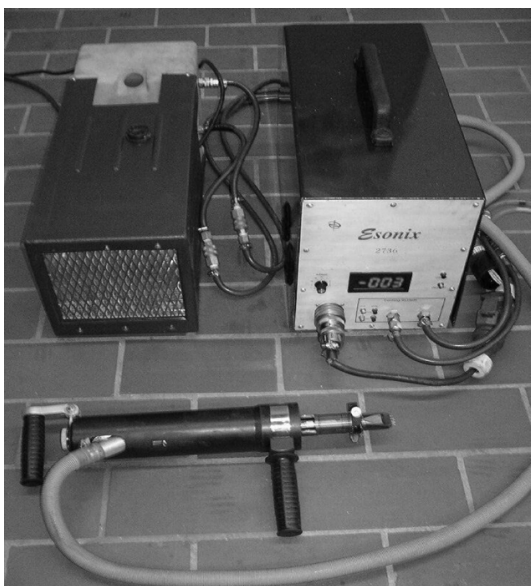

Fig. 3 UIT-equipment

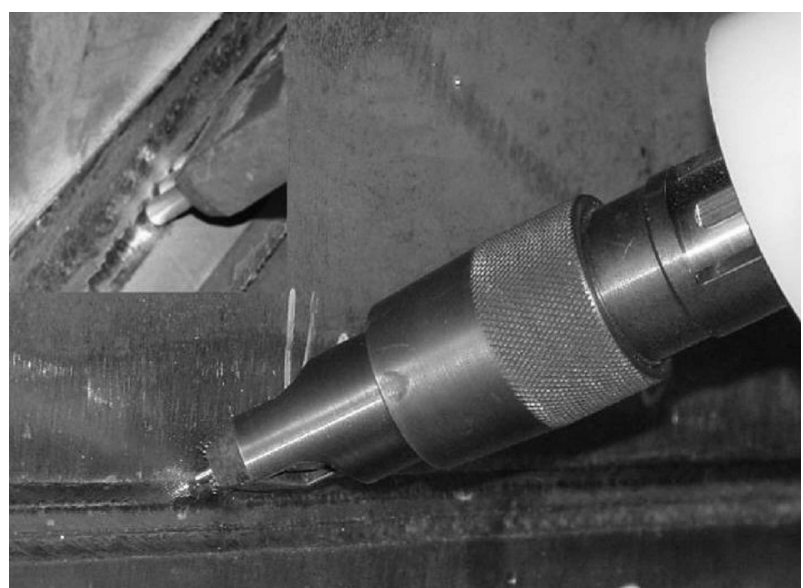

Fig. 4 Pin of UIT-equipment

\subsection{Benefits of UIT}

The operation of UIT is much more comfortable and effective compared to conventional hammer and needle peening methods because of the high frequency with low vibrations and noise evolution, leading to a high quality assurance. Compared to other strengthening measures UIT is very simple in use: it can be applied in minutes, it offers a high accessibility including e.g. overhead application and it does not require any bridge traffic to be detoured or altered. These features thus give UIT a great potential use especially as a retrofit measure to improve the service life time of existing structures.

\subsection{Enhancement of fatigue resistance using UIT}

Several investigations mostly in the U.S. showed a substantial enhancement in the fatigue performance for different welded construction details by UIT, see e.g. [6], [7]. Based on these existing and successful studies on UIT an extensive testing and research program was initiated at the University of Stuttgart and Weimar that aims to increase the application of high strength steels in bridge structures by applying modern post-weld treatment methods like TIG dressing or UIT to enhance the fatigue resistance, see [8], [9]. High strength steels are most suitable for the application of post-weld treatment methods like UIT as they can build up high compressive residual stresses, that suppresses the fatigue crack initiation and thus increase the fatigue resistance. Fig. 5 shows as an example of the aforementioned research program results of some residual stress measurements adjacent to the weld obtained by hole drilling before and after the application by UIT. It can clearly be seen, that the residual stress pattern is shifted from the tensile region - as it is typically the case in the as-welded state - to the compressive region and that the stress level almost reaches yield stress on the surface. Similar results are also reported in [6]. First fatigue test results carried out on small scale test specimens according to Fig. 8 for the steel grade S460 in the as-welded state and for UIT treated specimens after manufacturing can be seen in Fig. 6 . The tests were conducted with a constant amplitude stress range and a stress ratio of $R=0.1$. The test results given in the $\mathrm{S}-\mathrm{N}$ diagram reflect mean life lines obtained by linear regression analysis. It can be observed that there is a significant enhancement of the fatigue resistance by UIT compared to the as-welded state. In the given example the fatigue strength at $2 \cdot 10^{6}$ load cycles could be improved up to $100 \%$ through the application of UIT compared to the as-welded state. Additional test are underway to verify this results also for other steel grades and for full size girder tests [9]. 


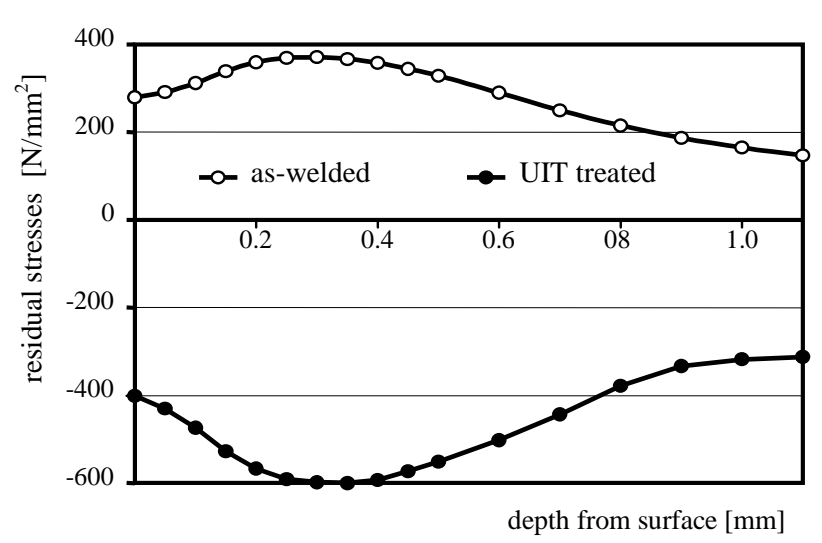

Fig. 5 Residual stresses adjacent to the weld [9]

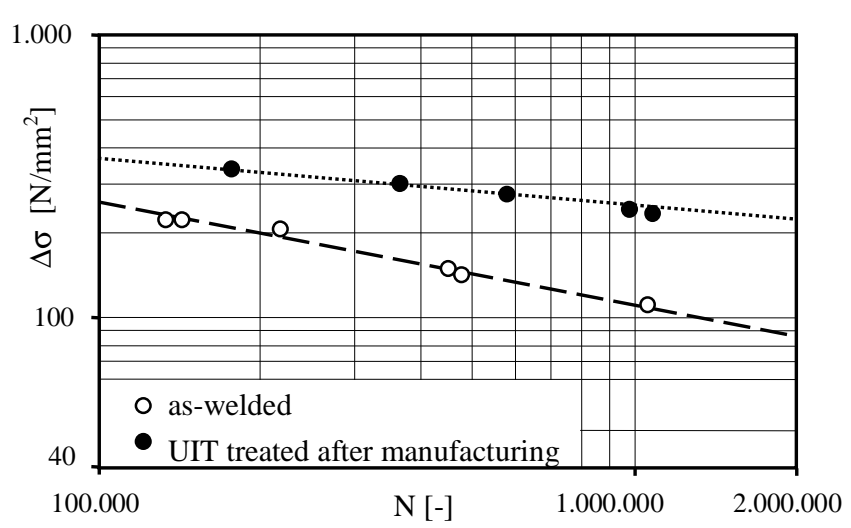

Fig. 6 S-N diagram [8]

\section{Experimental studies}

\subsection{Scope}

According to the above mentioned benefits UIT seems to be very much effective as a strengthening method to extend the service life of fatigue loaded welded details in the field of bridge structures. However, except for very few investigations [10], [11], all of the existing studies are focusing so far on improving the fatigue resistance of new manufactured/fabricated welded details. Based on this situation a small experimental program was initiated in the frame of a diploma thesis [12] in order to quantify the effectiveness of UIT as a strengthening measure to extend to the life time of partially damaged details typical in existing structures.

\subsection{Test program}

\subsubsection{Test specimens}

The fatigue tests have so far been conducted on small scale test specimens representing the common fatigue critical detail of a transverse stiffener that is fillet welded to the tension flange, see Fig. 7. The stiffeners were welded on both sides on the plates. All specimens were of steel grade S460M according to EN 10025-4 [13]. The particular geometry of the specimens is given in Fig. 8.

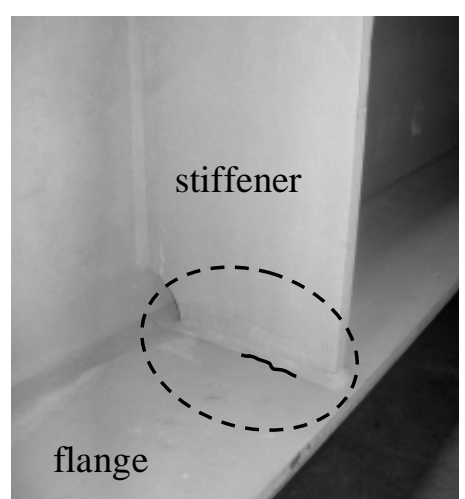

Fig. 7 Typical transverse stiffener detail of a steel bridge

\subsubsection{Fatigue test procedure}

As a first step of the fatigue test program as-welded details were loaded on a constant amplitude stress range with a stress ratio of $\mathrm{R}=0.1$ until complete fracture of the specimens. This allowed the definition of a reference S-N-curve for the as-welded details. Then in a next step similar test specimens where loaded with the same constant amplitude stress range up to about $75-90 \%$ of the 
life time of the as-welded details. This procedure thus aimed to simulate a certain amount of fatigue damage as it is e.g. the case in real structures in service. After that the specimens were removed in order to check for possible fatigue cracks at the toe of the transverse fillet weld to the flange. This was done by visual inspection assisted with a 10x magnifying glass and the magnetic particle inspection. For all test specimens no detectable fatigue cracks have been observed, meaning that according to the accuracy of the above mentioned non-destructive testing methods possible fatigue cracks have been smaller then $1.0 \mathrm{~mm}$ to $1.5 \mathrm{~mm}$ in depth. After the identification of the fatigue damage the specimens were UIT treated and again loaded by the same constant amplitude stress range until complete fracture.

\subsection{Fatigue test results}

The fatigue test results are plotted in a log-log S-N-diagram in Fig. 9. The dashed and doted lines represent again the S-N-curves for the as-welded condition and the UIT treated condition according to Fig. 6, where the UIT treatment was performed just after manufacturing of the specimens, meaning without any fatigue damage in advance.

The blank loops of the test data indicate the number of load cycles $\mathrm{N}_{T}$ when the as-welded specimens were UIT treated. These numbers of load cycles were chosen to approximately $\mathrm{N}_{\mathrm{T}} \approx 0.75-0.90 \cdot \mathrm{N}_{\mathrm{B}}$, whereby $\mathrm{N}_{\mathrm{B}}$ is the number of load cycles at failure of the untreated as-welded test specimens, reflected by the dashed line. This procedure allowed to simulate a certain amount of fatigue damage as it is the case in real structures under service condition. The final fatigue failure and life time $\mathrm{N}_{\mathrm{TB}}$ of these specimens are displayed by the filled out black loops. The number of load cycles between the blank and black loops $\left(\mathrm{N}_{\mathrm{TB}}-\mathrm{N}_{\mathrm{T}}\right)$ is thus the rate of the fatigue life extension of the partially damaged details strengthened by UIT. According to these results the fatigue life of the strengthened details could be extended in minimum by a factor of 2.5 of the time the specimens were treated. This minimum life time extension factor also indicates that under the given situation (provided there are no respectively shallow fatigue cracks) the fatigue resistance of the original detail can be restored through the application of the UIT treatment.

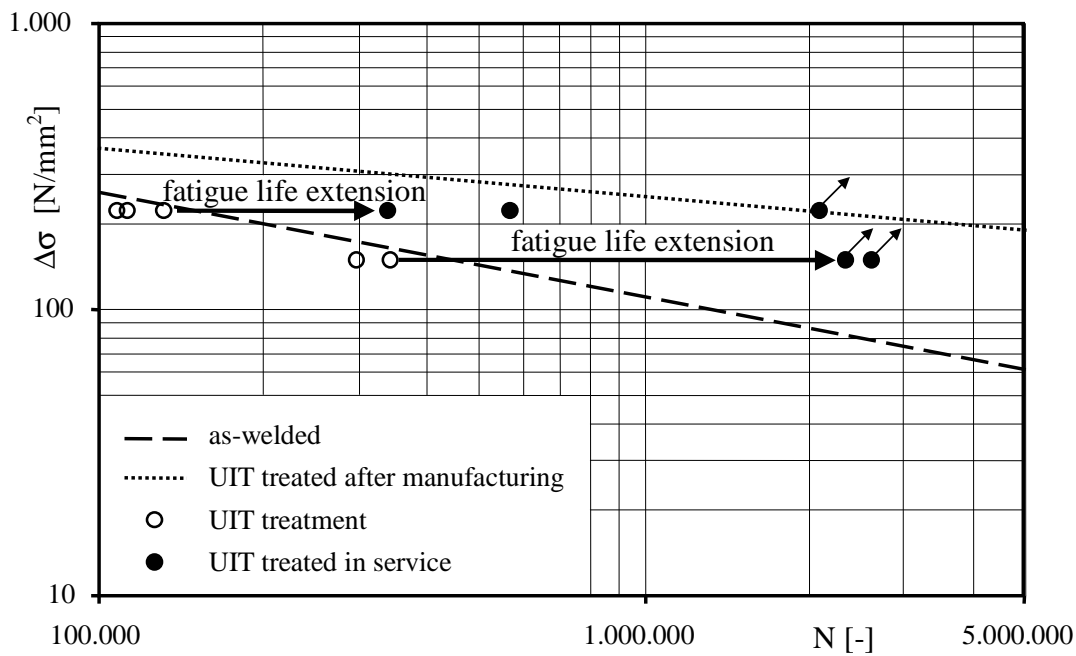

Fig. 9 Results of fatigue tests

\section{Conclusions and Outlook}

The work presented in this paper clearly indicates that UIT is an effective method to extend the fatigue life of welded details, not only for new manufactured structures but also for existing structures in service having a certain amount of fatigue damage. Especially for the latter application it could be shown by an experimental test program that the life time of fatigue damaged transverse stiffener detail could be extended at least by a factor of 2.5. This means that, for the given situation having no or shallow fatigue cracks, the fatigue resistance of the strengthened detail has been restored to the original one. Based on the existing test results further investigations are currently underway to develop a numerical fatigue-life prediction model using the local notch stress approach 
for the crack initiation phase and the fracture mechanic concept for the crack growth phase.

Compared to other repair or strengthening measures for fatigue prone details UIT seems to be a very economic solution as it is very simple in handling, quick in its performance on site and does not disturb any flow of traffic during its application. These practical aspects in combination with the technical feature to enhance the fatigue life will thus give UIT a great potential use by saving substantial time and costs within the ever increasing field of rehabilitation of existing structures like bridges.

In order to gain more knowledge on the effectiveness of various retrofit measures further studies are required to quantify important aspects as e.g. the rate of existing damage respectively the crack size or the effectiveness in real large-scale structures in order to come up with similar engineering design methods as they are available for new structures.

\section{Acknowledgement}

The authors acknowledge the work of Mr. André Muck who mainly did the experimental studies in the frame of his diploma thesis. Special acknowledgement is also given to Applied Ultrasonics providing the know-how for the treatment and to Eurosonix $^{\circledR}$ for providing the UIT-equipment and performing the treatment.

\section{References}

[1] FALKNER H., "Monitoring im Bauwesen: Eine Aufgabe auch für die Prüfingenieure ?", Der Prüfingenieur, Zeitschrift der Bundesvereinigung der Prüfingenieure für Bautechnik VPI, April 2004, pp. 38-44 (in German)

[2] “Assessment of Existing Steel Structures, Remaining Fatigue Life", European Convention of Constructional Steelwork (ECCS), Technical Committee 6 - Fatigue, in press., 2005

[3] MIKI C., ITO Y., SASAKI E., "Fatigue and Repair Cases in Steel Bridges", Tokyo Institut of Technology, Department of Civil Engineering, Miki Laboratory, 2003

[4] http://iiw-wg5.cv.titech.ac.jp/: International Institute of Welding (IIW), Commission XIII: Fatigue of welded structures, Working Group 5 (WG5), Repair of fatigue loaded welded structures, Homepage.

[5] STATNIKOV E. et al., "Ultrasound tool for strain strengthening and relaxation treatment" Patent of the RF No. 472782, 1975

[6] ROY S., FISHER J.W., BEN T.Y., "Fatigue resistance of welded details enhanced by ultrasonic impact treatment (UIT)", International Journal of Fatigue, No. 25, 2003, pp. 12391247.

[7] HAAGENSEN P., MADDOX S., "Post weld improvement for Steel and Aluminium Structures", International Institute of Welding (IIW), Doc. XIII-1815-00, Februar 2004.

[8] KUHLMANN U., et al., "Effective Use of High strength steels in welded structures under fatigue loading" In: Proceedings of the Eurosteel Conference 2005, 08-10 June 2005, Maastricht, The Netherlands

[9] DÜRR A., "Enhancement of the fatigue resistance of high strength steels by applying modern post-weld treatment methods", PhD-Thesis, University of Stuttgart, Institute of Structural Design, under preparation, 2006 (in German)

[10] KRISHNA K., VERMA P.E, STATNIKOV, E.S., THEINI L., "Improving Service Life of Steel Bridges, Light Poles and Sign Structures Through the Use of Ultra Sonic Impact Treatment (UIT)", Bridge Maintenance, Safety, Management and Costs, Watanabe, Frangopol \& Utsunomiya (eds.), Taylor \& Francis Group, London, 2004 
[11] CHENG X., FISHER J.W., YEN B.T., MA Z., „Fatigue Crack Inspection, Weld Repair and Post-Repair Fatigue Behavior of Stainless Steel Welded Components“, In: Proceedings of IABSE Symposium: Metropolitan Habitats and Infrastructure, Shanghai, China, September 2004.

[12] MUCK A., "Retrofitting of fatigue loaded welded structures by Ultrasonic Impact Treatment (UIT)", diploma thesis, University of Stuttgart, Institute of Structural Design, May 2005 (in German)

[13] EN 10025-4: Hot rolled products of structural steels - Part 4: Technical delivery conditions for thermomechanical rolled weldable fine grain structural steels, 2004 